\title{
SOBRE EL MUQTABIS
}

\section{LAS HIJAS DE AL-HAKAM I Y LA REVUELTA DEL ARRABAL}

\author{
MARIBEL FIERRO \\ CSIC - Madrid
}

Este trabajo nace de la lectura de la traducción del t. II/1 del Muqtabis de Ibn Hayyān llevada a cabo por M. ${ }^{\mathrm{c}} \mathrm{A}$. Makki y F. Corriente ${ }^{1}$, a cuyo esfuerzo por hacer accesible en español un texto difícil hemos de estar todos agradecidos. No hace falta recordar cuánto allana el camino la existencia de una buena traducción tanto a quienes saben árabe como a los que no lo saben ${ }^{2}$.

La reaparición del texto de Ibn Hayyān relativo al reinado de al-Hakam I, durante tanto tiempo dado por perdido ${ }^{3}$, va a permitir profundizar en un episodio de gran importancia para la historia de la dinastía omeya: «la revuelta del Arrabal», acaecida en Córdoba en el año 202/818, pues, en efecto, constituyó un momento crucial en el afianzamiento y consolidación del emirato omeya en la Península Ibérica. Dejo para otra ocasión un estudio, que se sigue echando en falta, sobre este episodio. Me voy a limitar ahora a llamar la atención sobre un breve pasaje que aparece en una de las versiones que se conservan al respecto.

La versión es la transmitida por el alfaquí Muhammad b. ${ }^{\complement} \bar{I} s a ̀ ~ a l-A^{c}$ s̀à $^{4}(a$ través de ${ }^{\complement}$ İsà b. Ahmad al-Rāzī) y reza así en la traducción de M. ${ }^{\mathrm{c}} \mathrm{A}$. Makki y F. Corriente:

1 V. nota 5 para la referencia de la publicación.

2 Tuve ocasión de comentar el tema aquí tratado con Federico Corriente, quien me animó a publicar algo al respecto en la reunión dedicada al vol. II/1 del Muqtabis, celebrada el 14 de junio de 2002 en el CSIC y organizada por E. Manzano y A. Canto García, dentro del proyecto de investigación «Madinat al-Zahrā’: representación y proyección del poder califal a través del registro material y textual».

3 V. al respecto M. Marín, «El "Halcón maltés" del arabismo español: el volumen II/1 de al-Muqtabis de Ibn Hayyän», Al-Qanțara XX (1999), 543-49.

${ }^{4}$ Se trata de un conocido ulema, fallecido en 221/835 ó 222/836. V. sobre él Marín, M., «Nómina de sabios de al-Andalus», Estudios Onomástico-Biográficos de al-Andalus. I, ed. Marín, M., Madrid, 1988, 23-182, n. ${ }^{\circ} 1291$, remitiendo a Ibn Hārit al-Jušanī, $A j b a \bar{r}$ al-fuqahä' wa-l-muhaddițin, ed. Ávila, M. L. y Molina, L., Madrid, 1992, n. ${ }^{\circ} 129$ y Qudāt Qurțba, ed. y trad. Ribera, J., Madrid, 1914, 10, 102-3; Ibn al-Faradī, Ta'rīj 'ulamā' al-Andalus, ed. Codera, F., 2 vols., Madrid, 1891-2, n. ${ }^{\circ} 1100$; al-Ḥumaydī, Ýad-

Al-Qantara XXIV, 1 (2003) 209-215 
La masa de los cordobeses volvió a tener fricciones con el emir, haciendo fintas a su lanza [la negrita es mía, M. F.], a maltratarlo y censurar su conducta, redoblándose su maldad en esto en el año $202 \mathrm{~h}$., pues se engolfaron en ello: no dejaban de murmurar, sus cabecillas recurrían a coloquios nocturnos en las mezquitas para ocultarse del sultán, contra quien conspiraban... ${ }^{5}$

La frase traducida como «haciendo fintas a su lanza» corresponde en el ms. al árabe al-gamz li-banāti-hi («haciendo guiños a sus hijas»), frase que ha sido corregida por los traductores por al-gamz li-qanāti-hi. La razón aducida es que «hacer guiños a sus hijas», según los traductores, «parece fuera de contexto, no siendo difícil en grafia árabe que un copista alterase qanāt en banāt».

Sin embargo, la frase que aparece en el manuscrito (al-gamz li-banāti-hi) debe ser mantenida, pues para enmendar una lectura clara y correcta, tanto desde el punto de vista morfosintáctico como semántico, se requerirían razones de peso. La única que se da en esa nota es que «hacer guiños» (luego volveré sobre el significado de $a l$-gamz) a las hijas del emir omeya "parece fuera de contexto». No se explica qué contexto es ése. Cabría interpretar que para los traductores (o para alguno de ellos), el hecho de que los cordobeses se permitiesen libertades con las hijas del emir omeya es algo inconcebible en dos sentidos:

1) cualquier atrevimiento con la parentela femenina de un musulmán es un insulto gravísimo en el que raramente se incurre, pues la "socialización»" islámica está dirigida precisamente a hacer inacessibles a otros hombres a las mujeres (esposas, hijas, otras parientes de sexo femenino) de un musulmán y a imponer unas normas de conducta que reduzcan cualquier referencia hablada a las mujeres y limiten el contacto con ellas por parte de extraños y aún parientes, sancionándose negativamente cualquier desviación de esas normas;

2) las hijas debían vivir recluidas en el ámbito privado de la residencia del emir, no estando expuestas a la vista de otros, de manera que hacerles guiños habría sido imposible.

wat al-muqtabis, ed. M. b. Tāwīt al-Țanŷī, El Cairo, 1952, n. ${ }^{\circ}$ 106; Ibn Hayyān, Muqtabis II/2, ed. Makki, M. 'A., Beirut, 1393/1973, 42, 57, 73, 81; al-Dabbī, Kitāb bugyat al-multamis fi ta'rij riŷāl ahl al-Andalus, ed. Codera, F. y Ribera, J., Madrid, 1884, n. ${ }^{\circ}$ 212; 'Tyād, Tartīb al-madārik, varios editores, 8 vols, Rabat, ...-1983, IV, 114-6; al-Maqqarī, Naf̣̣ al-țīb, ed. 'Abbās, I., 8 vols., Beirut, 1968, I, 501. Estudios que lo mencionan son López Ortiz, J., La recepción de la escuela malequí en España, Madrid, 1931, 192; Makki, M. ${ }^{\mathrm{c}} \mathrm{A} .$, Ensayo sobre las aportaciones orientales en la España musulmana y su influencia en la formación de la cultura hispano-árabe, Madrid, 1968, 184 y «al-Tašay$\mathrm{yu}^{\mathrm{c}}$ fī l-Andalus», R.I.E.E.I.M. II (1954), 93-149, 104.

5 Ibn Hayyan (sic), Crónica de los emires AlHakam I y $\{$ Abdarrahmān II entre los años 796 y 847 [Almuqtabis II-1], traducción, notas e índices de Mahmmūd SAlī Makkī y Federico Corriente, Zaragoza, 2001, 105r / 60. 
La normativa legal y religiosa islámica se encamina, desde luego, en ese sentido ${ }^{6}$. Pero doctrina y práctica no van siempre unidas. Además, dentro de la cultura árabe existe una fuerte tradición de sátira y ataques personales que se ceban también en las mujeres ?

No hay que descartar, por tanto, la posibilidad de que los cordobeses se mostrasen irrespetuosos con las hijas del emir. No está claro, sin embargo, en qué consistió exactamente la conducta irrespetuosa: ¿las calumniaron? ¿les hicieron guiños o señas? ¿las llegaron a tocar? Todas estas interpretaciones son posibles ${ }^{8}$. El decidirse por una de ellas requeriría que pudiésemos fijar con precisión el grado de exposición pública que pudieron tener las hijas de al-Hakam I. Lo que me parece evidente es que no debemos presuponer que ese grado haya sido siempre el mismo para todas las princesas omeyas. Y es más probable que fuese mayor en época de al-Hakam I que en épocas posteriores.

Una de las consecuencias de la revuelta del Arrabal fue que el emir omeya se hizo más inaccesible a sus súbditos. Al-Hakam I nos es presentado en algunos textos actuando de una manera que sería inconcebible entre sus sucesores. Por ejemplo, el emir le dice a uno de los rebeldes, el alfaquí árabe Ṭālūt b. ${ }^{\mathrm{C}} \mathrm{Abd}$ al-Yabbār al-Ma ${ }^{\mathrm{c}} a \overline{f i r i ̄}$ :

"iṬâlūt, loor a Dios que te ha puesto en mis manos, ay de tí! Dime: si tu padre o tu hijo hubiesen ocupado mi lugar en este Alcázar, ¿te habrían tratado con mayor honor y consideración que yo lo he hecho? ¿Acaso alguna vez te rechacé en cosa que me pidieras para tí u otra persona? ¿No participé de tus dulzuras y amarguras? ¿No te visité en tus enfermedades? ¿No compartí tu tristeza por tu mujer, yendo a pie en su funeral hasta el Cementerio del Arrabal, y luego volví contigo también hasta tu casa? ¿He hecho contigo algo que no fuera honrarte y enaltecerte? ¿Qué te empujó, pues, a corresponder a mis favores con nada menos que querer deponerme de mi reino, matarme, declarar presa lícita a mis mujeres y violar mi intimidad?» ${ }^{9}$.

6 V. Marín, M., Mujeres en al-Ándalus, Madrid, 2000, 177-252. También pueden consultarse los artículos de Adang, C. («Women's access to public space according to al-Muhalla bi-äthār») y de la Puente, C. («Juridical sources for the study of women: limitations of the female's capacity to act according to Mālikī law») en Marín, M. y Deguilhem, R. (eds.). Writing the feminine. Women in Arab sources, Londres, 2002, 75-94 y 95-110.

7 V. el caso del poeta Ibn Šuhayd en Marín, Mujeres, 231-2. V. también Garulo, T., Ibn Sāra al-Šantariñi. Poemas del fuego y otras casidas, ed., trad. y estudio, Madrid, 2001, 27-30.

${ }^{8}$ Para los distintos significados de al-gamz, v. E. W. Lane, Arabic-English Lexicon. Carmen Barceló me indica que la traducción más apropiada es la de «guiñar el ojo a alguien», significado que tiene hasta hoy el verbo gamaza li-, señalándome también que, según Ibn Manzūr en su Lisān al-'arab, al-gamz deriva su significado de Corán 83: 29-30: «Los pecadores se reían de los creyentes / Cuando pasaban junto a ellos, se guiñaban el ojo» (trad. Julio Cortés).

${ }_{9}$ Muqtabis II/1, 110v/76-7. 
Ningún emir omeya posterior a al-Hakam I habría acompañado a pie el cortejo fúnebre de una mujer por las calles de Córdoba. En ese relato, la figura de al-Hakam I se asemeja a la de un primus inter pares. En cambio, de su sucesor ${ }^{\circ} \mathrm{Abd}$ al-Rahmān II se dice que «fue el primero que introdujo la pompa en el califato en Alandalús, organizando el protocolo real y absteniéndose del roce con la plebe» ${ }^{10}$.

Además, en las distintas versiones de que disponemos de la revuelta del arrabal es frecuente la referencia al trato poco respetuoso con el emir por parte de los cordobeses. Valga como botón de muestra el siguiente relato de Ahmmad b. Muḥammad b. Jalaf al-Warrāq:

La mayoría de la gente del Arrabal mayor de la margen del río, que provocaron la gran rebelión que lleva su nombre, era una grey ínfima, un ganado de ignorantes y groseros, que despreciaban al emir con descaro, rebuscando anécdotas y calumniando su conducta, sin guardarle ningún respeto, ni cesar de fustigar con sus lenguas a sus esclavos extranjeros y guardia personal, a los que abordaban en las reuniones con soeces expresiones. Su falta de respeto al emir llegó al punto de que por la noche lo llamaban desde lo alto de los minaretes, reprochándole su ociosidad y sacando a relucir sus defectos, gritándole: «A la oración, borracho!», violando así su intimidad.

Su osadía llegó al punto de que, cierto día que salió a holgarse cazando a la zona de la Campiña, al pasar por el Puente y cruzar el mercado del Arrabal, empezaron a decirle cosas y hacerle insinuaciones y le dieron palmas ${ }^{11}$.

Hay una frontera muy fina entre esta conducta y ese al-gamz li-banāti-hi descrito por al-A $\mathrm{A}^{\mathrm{s} a ̀ a}$, aunque en el relato de al-Warrāq no hay referencia alguna a que el descaro de los cordobeses se extendiese a las hijas del emir. Si

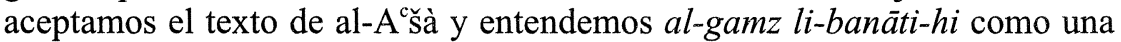
acción que implica que los cordobeses descarados y las hijas del emir comparten un mismo espacio, ¿en qué circunstancias pudo darse esa situación? ¿Una celebración religiosa? ¿Una salida de la ciudad en la que el emir iba acompañado por sus hijas? ${ }^{12}$.

Las circunstancias también dependen de cómo interpretemos quiénes eran los cordobeses descarados. Los textos recogidos en el Muqtabis dejan clara la participación de miembros de las élites cordobesas en la revuelta. Entre ellos se cuentan alfaquíes de origen árabe, como el ya mencionado Țālūt $b .{ }^{c} \mathrm{Abd}$ al-Ŷabbär al-Ma āfirī ${ }^{13}$, personaje que dio su nombre a una mezquita cordo-

${ }_{10}$ Muqtabis II/1, 140v/ 172

11 Muqtabis II/1, 111r/78. La nota 133, en la que se explica qué hay que entender por «violación de intimidad», no deja de tener resonancias de actualidad.

12 Para estas posibilidades es de obligada consulta el libro de Marín citado en la nota 6.

13 V. Marín, «Nómina», n. ${ }^{\circ} 645$, citando Ibn al-Qūtiyya, Ta'rỉj iftitāh al-Andalus, ed. y trad. Ribera, J., Madrid, 1926, 53; 'Iyād, Tartīb al-madārik, III, 340-2; Ibn al-Abbār, 
besa, y el de ‘ĩsā b. Dīnār al-Gāfiqī. Otro participante fue el famoso alfaquí de origen beréber Yahyà $b$. Yahyà al-Layțî, miembro de una familia que servía a los omeyas en el ejército y en la jidma ${ }^{14}$. Sin embargo, la versión oficial omeya, la que se recogió en el «parte de la victoria» enviado a las provincias para ser leído públicamente, silencia totalmente esta participación de miembros de las élites y presenta la revuelta como obra de «los depravados, la canalla y la gente ínfima de Córdoba, 'esparteños' de corto alcance y rústicos, en actitud petulante e insolente» ${ }^{15}$. Pero esto es claramente propaganda. La revuelta contra el emir no fue una revuelta de «muladíes» ${ }^{16}$, sino una revuelta de habitantes de Córdoba pertenecientes a distintos grupos sociales, unidos todos ellos contra un emir que intentaba aumentar la presión fiscal sobre los cordobeses (de una forma que se sintió entonces como abusiva en tanto que se apartaba de la práctica existente) y que para imponer esa nueva fiscalidad estaba reclutando soldados que dependían únicamente de él, sin lazos con la población local. Los que apoyaron al emir fueron precisamente esos soldados de origen esclavo, así como sus parientes omeyas y sus clientes, es decir, aquellos sectores que podían beneficiarse del incremento en la presión fiscal.

La represión de los rebeldes por parte del emir fue brutal. Algunas de las versiones de esa represión insisten en que esa represión no afectó a las mujeres:

... Fue un suceso terrible para ellos, pues muchos murieron y el corazón de todos quedó lleno de terror, aunque el emir había ordenado respeto a las mujeres e indulgencia con los menores ${ }^{17}$.

Takmila, ed. 'Izzat al-'Attār al-Husaynī, 2 vols., El Cairo, 1375/1955-6, n. ${ }^{\circ}$ 931; al-Marrākušī, al-Dayl wa-l-Takmila, varios eds., 8 vols, ...-1984, IV/2, 274; Ibn Sa Sīd, al-Mugrib fí hulà l-Magrib, ed. Dayf, Š., 2 vols., El Cairo, 1953-55S, I, 43; Ibn al-Jatịib, Kitâb a $a^{c}$ āl al-a läm, ed. Lévi-Provençal, E., Beirut, 1956, 15.

14 V. sobre los dos últimos personajes Fierro, M., «El alfaquí beréber Yahyà $b$. Yahyà, 'el inteligente de al-Andalus'», Estudios Onomástico-Biográficos de al-Andalus. VIII, ed. Ávila, M. L. y Marín, M., Granada / Madrid, 1997, 269-344. Una de las versiones de la revuelta del Arrabal recogida por Ibn Hayyān, la de al-Hasan b. Muhammad b. Mufarriŷ (quien cita al secretario Sakan b. Ibrāhīm), sitúa la participación de algunos de estos personajes en una revuelta anterior que habría tenido lugar unos años antes.

${ }_{15}$ Muqtabis $\mathrm{II} / 1,104 \mathrm{r} / 57$.

16 Contrariamente a lo que parecen indicar los traductores: v. su nota 93. Aprovecho para señalar que en la p. 69 de la traducción se hace de «origen muladí» a los famosos Banū Hudayr, cuando el texto árabe deja claro que son mawälī. Clientes y muwalladūn son dos grupos sociales que no deben ser confundidos y, sobre todo, no se debe extender abusivamente el uso de muwallad o muladí para designar a los autóctonos. He hablado de este asunto en mi artículo "Cuatro preguntas en torno a Ibn Hafsūn», Al-Qanțara XVI (1995), 221-257 y más en detalle en «Mawälī and muwalladūn in al-Andalus (second/eighth-fourth/tenth centuries)», Mawälī in the Islamic World, ed. Nawas, J. y Bernards, M., en prensa. 56-7.

${ }^{17}$ Esta versión procede de Aḥmad b. Muhammad al-Rāzĩ: Muqtabis II/1, 103v / 
El emir Alḥakam respetó a las mujeres de los del Arrabal, protegiéndolas e impidiendo fueran dañadas. Ordenó reunirlas en un lugar donde se las guardó hasta que se dispersaron, compadecido de ellas y sus hijos y demostrando en ello toda su buena voluntad ${ }^{18}$.

Quedaron ante él derrotados, y él declaró presa legítima sus hogares del Arrabal grande y los otros, aunque respetando a sus mujeres ${ }^{19}$.

Pero hay otra versión según la cual «El emir al-Hakam declaró presa lícita a las mujeres de los del Arrabal y sus secuaces de los otros arrabales de Córdoba, así como autorizó todo acto de muerte, saqueo e incendio durante tres días...» ${ }^{20}$. Posiblemente no sea casual que la única versión en la que se reconoce que la brutalidad se extendió a las mujeres (en contra de lo establecido en el derecho islámico ${ }^{21}$ ) sea la versión procedente del secretario Sakan b. Ibrāhīm ${ }^{22}$, mientras que en las que proceden de ulemas como al-A $\mathrm{A}^{c}$ s̀a o Ibn Mufarriŷ se insista en la corrección de la conducta del emir.

No me cabe duda de que la versión de Sakan b. Ibrāhīm refleja mejor lo que debió ocurrir. Los relatos que se conservan de la revuelta del Arrabal están mediados todos ellos (en grado mayor o menor, divergencia que los hace especialmente interesantes) por la necesidad de exculpar al emir de lo que fue una represión brutal que afectó a diversos grupos sociales cordobeses. Puesto que afectó a miembros de las élites, esa exculpación se hizo necesaria a la hora de buscar un nuevo acomodo tras la victoria del emir que permitiese la reconstrucción de los lazos entre las antiguas élites arabo-beréberes y los omeyas. La exculpación tomó diversas formas, cuyo estudio permitirá ahondar en nuestro conocimiento del proceso de legitimación de los omeyas andalusíes. Una de esas formas es la recogida en la versión de al-A $\mathrm{A}^{\text {šà: }}$ se silencia el maltrato a las mujeres de los rebeldes y se carga a éstos con la culpa de haber insultado el honor del emir en la figura de sus hijas ${ }^{23}$. El transmisor de esta versión, Muhammad b. Sa ${ }^{c} 1 \bar{d}$ al-A $\mathrm{A}^{\complement}{ }^{\mathrm{s}} \mathrm{a}$, era sobrino por parte ma-

18 Ibid., 106v / 65.

19 Ibid., 109r / 72.

20 Ibid., $110 \mathrm{v}-111 \mathrm{v} / 78-9$

21 V. Abou el Fadl, Kh., Rebellion and violence in Islamic law, Cambridge, 2001 (cf. la reseña de D. Serrano en este mismo número de Al-Qantara).

${ }_{22}$ Sobre el cual puede verse Marín, «Nómina», n. ${ }^{\mathrm{o}} 579$ y Ávila, M. ${ }^{\text {a }}$ L., «Obras biográficas en el Muqtabis de Ibn Hayyān», Al-Qanțara X (1989), 480.

23 En este mismo relato se da la vuelta a una de las razones aducidas para explicar la revuelta, la anécdota del herrero y el soldado. La versión predominante es que el soldado del emir atacó al herrero y la muerte de éste desencadenó la revuelta (v. Lévi-Provençal, E., Histoire de l'Espagne musulmane, 3 vols., París/Leiden, 1950-3, 166). Pero

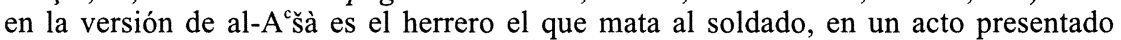
como fruto de la premeditación. No sólo se exculpa al emir, sino también a sus hombres. 
terna de Ṭālūt b. ${ }^{c} A b d$ al-Ŷabbār al-Ma āfirī, quien, como hemos visto, fue un destacado participante en la revuelta. Pero a diferencia de otros participantes, muertos y crucificados públicamente como escarmiento para toda la población cordobesa, Țālūt pudo salvar la vida y obtuvo finalmente el perdón del emir, llegando a tener excelentes relaciones con él. No parece casual que sea un pariente suyo, miembro de esa aristocracia árabe que sobrevivió a la masacre y llegó a un entendimiento con la dinastía omeya ${ }^{24}$, el que produjese una versión tan favorable a al-Hakam I.

${ }^{24}$ La política del «palo y la zanahoria» fue tan efectiva en al-Andalus como en otras regiones del mundo islámico: v. al respecto Athamina, K., «The 'ulamā' in the opposition: the "stick and carrot" policy in early Islam», The Islamic Quarterly 36 (1992), 153-78. 